\title{
Regeneration of a Central Synapse Restores Nonassociative Learning
}

\author{
Barbara K. Modney, ${ }^{1}$ Christie L. Sahley, ${ }^{2}$ and Kenneth J. Muller ${ }^{3}$ \\ ${ }^{1}$ Department of Biology, Cleveland State University, Cleveland, Ohio 44115, 2Department of Biological Sciences, Purdue \\ University, West Lafayette, Indiana 47907, and ${ }^{3}$ Department of Physiology and Biophysics, University of Miami School of \\ Medicine, Miami, Florida 33136
}

Sensitization is a form of nonassociative learning in which a strong or noxious stimulus persistently enhances the response produced by a weaker stimulus. In the leech Hirudo medicinalis, the S-interneuron is required for sensitization of the shortening response. A single S-cell axon was surgically separated from its sole synaptic partner, the neighboring S-cell. This consistently eliminated sensitization without impairing reflexive shortening itself, as measured in semi-intact specimens. Sensitization of the shortening reflex returned after 3 weeks when the severed axon grew and regenerated its specific electrical synapse within the nerve cord, as shown by restored conduction of impulses between S-cells. This confirms the essential role of one neuron, the S-cell, in sensitization, and it demonstrates that regeneration of the synapse between S-cells restores this example of nonassociative learning.

Key words: invertebrate learning; leech; regeneration; nerve repair; nonassociative conditioning; plasticity; axotomy; Hirudo medicinalis; S-cell; synapse regeneration
A major challenge in repair of the damaged CNS is to restore sensory function and motor performance (Freed et al., 1985; McClellan, 1992; Muller and Aguayo, 1992; Salzman and Faden, 1994; Engberg, 1995; Nicholls and Saunders, 1996), but in addition restoration of plastic properties such as learning and memory is surely required for full function. Little is known of prospects for recovery of even simple, nonassociative learning. Some function may return even without regenerative repair, and this may account for some recovery after mammalian CNS injury, but regeneration of specific connections may be needed to restore full function.

Some understanding of the synaptic connections and other neuronal circuitry underlying activity-dependent changes in behavior, including nonassociative learning, has come from studies of invertebrates, in which particular neurons can be reliably impaled with microelectrodes and identified as to function (Carew and Sahley, 1986; Byrne and Crow, 1991; Hawkins et al., 1993). Unfortunately, for most of the behaviors studied, scores of neurons are recruited without a single neuron having been shown to be essential (Zecevic et al., 1989). This includes such changes in simple reflexes as (1) habituation, in which the reflexive response to a repeated weak stimulus declines without diminished sensory or motor function; (2) dishabituation, in which the habituated response to the weak stimulus increases after a noxious stimulus; and (3) sensitization, in which a noxious stimulus enhances the response to a weaker stimulus.

An exception has recently been found in the leech, in which a single S-interneuron is essential for sensitization and full dishabituation of the shortening reflex (Sahley et al., 1994). Shortening

Received April 8, 1997; revised June 2, 1997; accepted June 2, 1997.

This work was Supported by United States Public Health Service, National Institutes of Health Grants HD 33392, MH44789, and NS34927 and a Whitehal Foundation Grant. We thank Drs. John Bixby and Don Ready for useful comments on this manuscript.

Correspondence should be addressed to Dr. Barbara K. Modney, Department of Biology, Cleveland State University, 2399 Euclid Avenue, Cleveland, OH 44115.

Copyright (C) 1997 Society for Neuroscience $0270-6474 / 97 / 176478-05 \$ 05.00 / 0$ is produced by mechanical or electrical stimuli that activate touch and pressure sensory neurons (Boulis and Sahley, 1988; Sahley and Ready, 1988). The S-cell of each segmental ganglion projects an axon toward the next anterior and posterior ganglia (McGlade-McCulloh and Muller, 1989); approximately halfway between ganglia, it makes an electrical synapse with its S-cell homolog (Fig. 1). Within its ganglion, each S-cell is excited by mechanosensory neurons and interneurons (not shown) and in turn excites the $\mathrm{L}$ motor neuron, which is among the motor neurons that shorten the segment. The reflex circuitry of Figure 1 illustrates how sensory stimulation excites the S-cell, which in turn excites the L motor neuron, activating longitudinal musculature, thereby increasing reflexive shortening. It has been observed that the activity of the S-cell increases when the shortening reflex is sensitized or dishabituated, and that S-cell activity and sensitization of the reflex are correlated, but that in the absence of sensitization or dishabituation there is no correlation between S-cell activity and reflex shortening. Selective ablation of single S-cells has confirmed the need for the S-interneuron to produce sensitization of the reflex, but ablation of S-cells does not diminish the reflex or its habituation (Sahley et al., 1994). Modification of the animal's shortening reflex therefore seems to depend on an intact chain of electrically coupled S-cells.

Previous studies using primarily electron microscopy and intracellular electrophysiology have shown that the severed S-cell axon accurately regenerates its synapse midway between ganglia specifically with its single target, the neighboring S-cell (Muller and Carbonetto, 1979; Scott and Muller, 1980). Therefore, we can test (1) whether breaking the S-cell chain will interfere with sensitization of shortening and (2) whether behavioral function returns when the synapse regenerates.

\section{MATERIALS AND METHODS}

Leeches and surgery. Specimens of Hirudo medicinalis were obtained from a commercial supplier (Leeches USA, Westbury, NY) or were bred in the laboratory. The tip of a 27 gauge hypodermic needle was used as a scalpel to cut axons in the medial connective nerve including the S-cell 


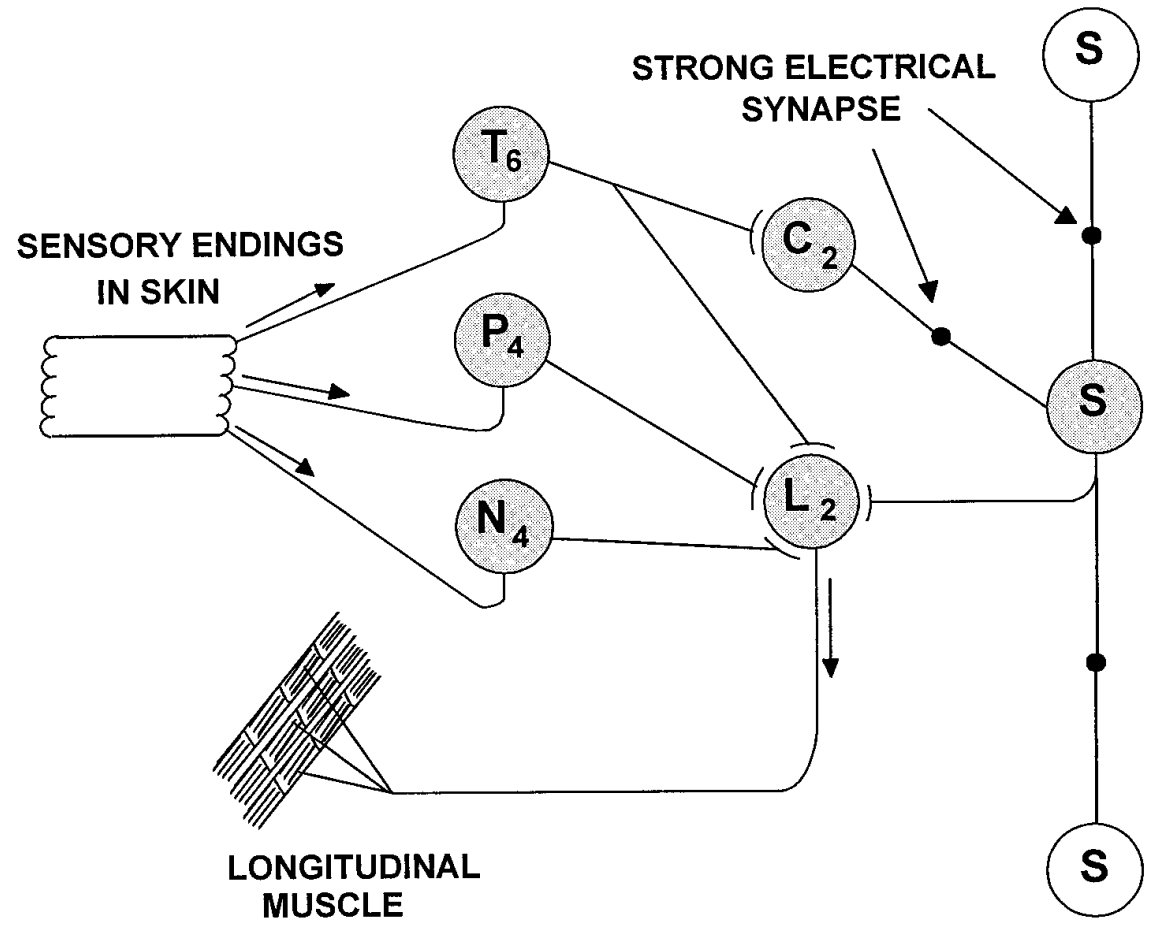

Figure 1. Elements of the sensory motor reflex, including sensory and motor connections with the S-cell. $\dashv$, Excitatory synaptic connections, both chemical and rectifying electrical; $\boldsymbol{\bullet}$, strong, nonrectifying electrical connections. The touch $(T)$ cells excite the S-cell through a disynaptic pathway, with coupling interneurons $(C)$ interposed. The $\mathrm{S}$-cell in each ganglion is linked to the S-cells in the neighboring ganglia (shown without shading, distances not drawn to scale). The synapses are electrical. The S-cell and the $\mathrm{T}$, pressure $(P)$, and nociceptive $(N)$ sensory neurons each excite the $\mathrm{L}$ motor neuron, innervating longitudinal musculature, thereby shortening the leech. In addition, there are apparently connections of $\mathrm{P}$ and $\mathrm{N}$ cells with the S-cell (not shown) (Shaw and Kristan, 1995), perhaps indirectly through C cells. Subscripts refer to the number of cells of each type within the ganglion. axon. Cuts were made anterior to ganglion 7 to interrupt the S-cell chain and not injure the S-cell in ganglion 4, which was ablated in earlier experiments (Sahley et al., 1994). Postsurgical recovery occurred in individual containers at room temperature $\left(\sim 21^{\circ} \mathrm{C}\right)$ in artificial spring water $[0.5 \mathrm{gm}$ of Forty Fathoms (Marine Enterprises, Towson, MD) artificial seawater per liter of distilled water] (McGlade-McCulloh and Muller, 1989) until testing and recording. For sham operations, an incision was made in the body wall without severing the nerve. Animals were coded to permit double blind experimentation; all survived the surgery.

Experimental preparation and protocol. To test for disconnection of the S-cells or for regeneration of the synapse between them, transmission between them was determined by stimulating and recording with suction electrodes applied to the connectives, measuring the propagation of the S-cell action potential through the lesion (Muller and Carbonetto, 1979). Extracellular recordings can detect the distinctive S-cell action potential, because its amplitude is the largest, its conduction is the most rapid, and its firing threshold to extracellular stimulation is the lowest of all axons in the connectives (Frank et al., 1975; Muller and Carbonetto, 1979). To confirm, for preparations in which only Faivre's nerve was cut, that extracellular recordings are valid for demonstrating disconnection and regeneration of the connection (Muller and Carbonetto, 1979), a separate group of operated specimens was tested with both intracellular and extracellular recording. Intracellular recordings were made from S-cell somata during extracellular stimulation and recording on opposite sides of the lesion.

Semi-intact preparations were used to assess nonassociative learning of the shortening reflex at two times, 5-8 d and 3-7 weeks after surgery, which were preceding and following the period of expected reconnection (Fig. 2). The leech was anesthetized on ice, its anterior sucker tethered to a tension transducer, its body pinned to a silicone rubber-coated dish, and its nerve cord exposed in physiological saline (Nicholls and Baylor, 1968) from ganglia 8-10. Teflon-coated silver wires connected to a stimulator (S88 and SIU5; Grass Instruments, Quincy, MA) were threaded beneath the skin in segments 4 or 5 and in 11 or 12 , with the coating scraped away from that region of the wire beneath the skin. Body shortening was elicited by a capacity-coupled 3-6 V, 3 msec stimulus delivered to segment 4 or 5 through the Teflon-coated silver wires, with the precise magnitude of the stimulus set to a level just above threshold for shortening. The average behavioral response (tension) to the first two stimuli at this level was assigned a magnitude of $100 \%$, and all subsequent responses were expressed as a percentage of the initial response. In absolute terms, this tension was typically $0.08-0.09 \mathrm{~N}$. The sensitizing stimulus, applied to the leech at segment 11 or 12 , was two trains of 10
3 msec stimuli set to a level $3 \mathrm{~V}$ above threshold delivered at $10 \mathrm{~Hz}$ with a 2 min interstimulus interval. Sham controls were operated on at the same time as the experimental groups, but the exposed connectives were not cut. No sensitizing stimulus was delivered to the habituation controls, which were not operated on. Transmission between S-cells was assessed after behavioral training using extracellular stimulation and recording with suction electrodes applied to the connectives.

Data analysis. A mixed two-factor ANOVA was used to compare the performance of sham and habituated control animals with axotomized animals across trials. To determine the significance of sensitization in the long-term regenerated group and of the lack of sensitization in the short-term group, a Newman-Keuls post hoc analysis of the significant ANOVA group main effect was used. The amplitudes of the initial, baseline responses in axotomized and sham specimens were compared using Student's $t$ test.

\section{RESULTS}

\section{Effect of cutting the S-cell axon}

Intracellular and extracellular recordings were obtained from three specimens about 1 week after surgery (short-term, Fig. $3 B$ ) and 2 long-term specimens more than 3 weeks and up to 11 weeks after surgery (long-term, Fig. 3C). Transmission of S-cell action potentials across the lesion was absent in the short-term preparations and present in the long-term preparations. Stimulation with the intracellular microelectrode verified the identity of the extracellularly recorded impulses (Fig. 3D). Similar results were obtained whether the anterior or posterior connectives were stimulated. These specimens were not examined behaviorally.

One group of animals was given sensitization training in a semi-intact preparation 7-9 d after surgery. Afterward their nerve cords were tested for conduction of S-cell action potentials across the lesion site, using extracellular recording and stimulation. For all the lesioned specimens $(n=9)$, the cut stopped the conduction of action potentials, which remained interrupted; i.e., no action potentials initiated anterior to ganglion 6 were recorded in the connective posterior to ganglion 7 , whereas for all sham $(n=10)$ and unoperated habituation $(n=7)$ controls conduction was intact. 


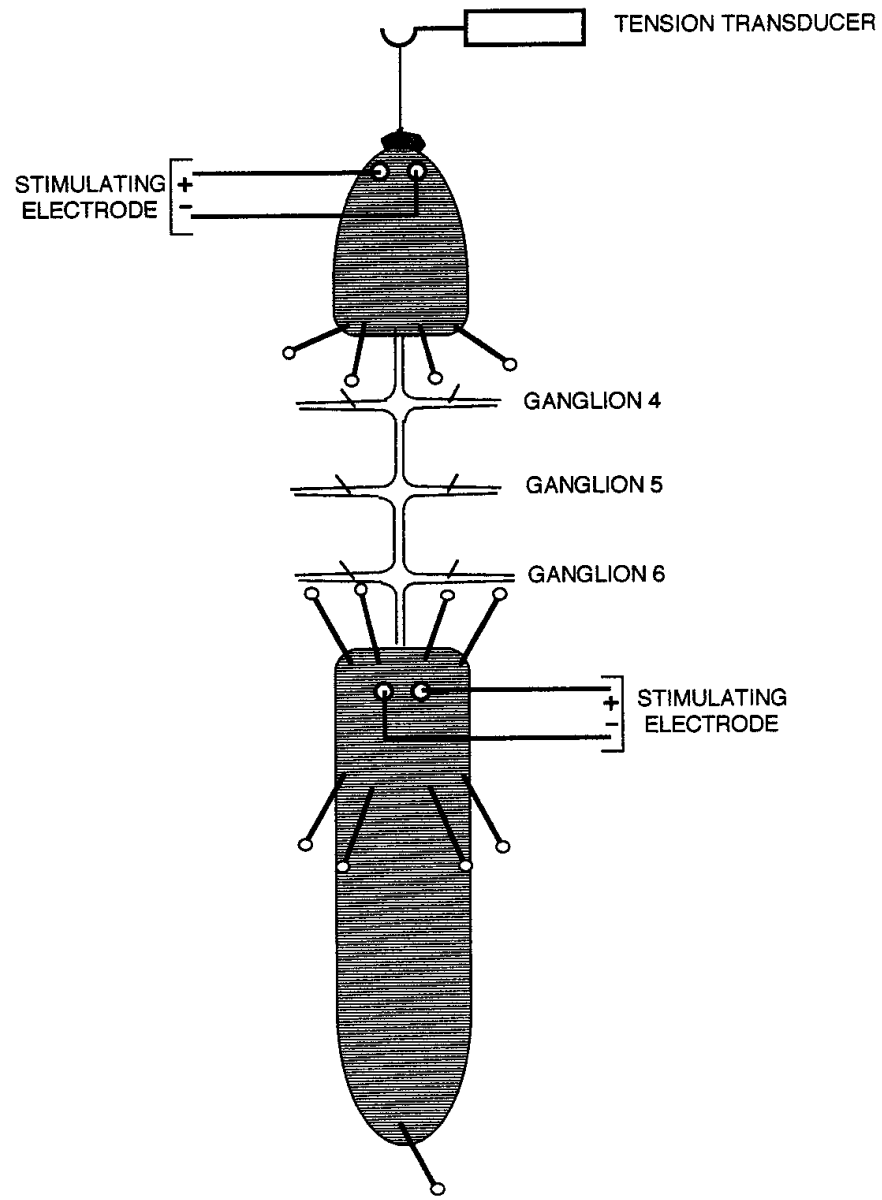

Figure 2. Schematic diagram of the semi-intact leech preparation, dorsal view, showing tension transducer attached to the anterior (top) and placement of stimulating electrodes on skin. The test and habituating stimuli were delivered to the anterior region of the animal, whereas sensitizing stimuli were delivered to the posterior region, as shown. Placements of pins, including one in the posterior sucker, are also indicated. The S-cell axon was cut anterior to ganglion 7, between 6 and 7 , which in the figure is at the anterior margin of the posterior portion of the animal.

Analysis of the behavioral testing revealed that the shortening reflex in axotomized animals was not sensitized relative to sham animals (mixed two-factor ANOVA, $F_{(2,22)}=9.87 ; p<0.001$ ) and was similar to habituation-control specimens (Newman-Keuls analysis of the significant ANOVA group effect, $p=0.6$ ) (Fig. 4). In contrast, the difference between axotomized and sham specimens was significant at the $p<0.05$ level. Because data normalized as a percentage of the initial, baseline response could mask lesioninduced changes in the size of the reflex, the absolute magnitude of the baseline shortening reflex was also compared using raw data. Comparison of the amplitude of baseline responding indicated no significant differences in the magnitude of the baseline reflex between the axotomized and sham specimens $\left(t_{(12)}=0.72 ; p>0.7\right)$.

\section{Measurement of sensitization after axon and synapse regeneration}

By 3 weeks, $\geq 80 \%$ of severed S-cell axons can regenerate functional connections (Muller and Carbonetto, 1979; Scott and Muller, 1980; Mason and Muller, 1996). Therefore, leeches were examined 3-6 weeks after surgery to determine whether restoration of conduction through the S-cell chain restores sensitization of the shortening reflex. At this time, the perfor- mance of leeches in the experimental group was not significantly different from that of leeches in the sham group (Fig. 5). Both showed significant sensitization compared with the habituation-control group $(n=7)$ (Newman-Keuls post hoc analysis of the significant ANOVA group main effect, $F_{(2,20)}=$ 3.69; $p<0.05$; Newman-Keuls, $p<0.05)$. Extracellular recording of S-cells showed that for all 19 leeches in the sham group (combined short- and long-term shams), S-cell action potentials that were initiated anterior to ganglion 6 propagated into the connective posterior to ganglion 7. Consistent with regeneration of the $\mathrm{S}$-cell axon and synapse, conduction along the S-cell chain and across the lesion site (anterior 6-posterior 7) was observed in six of the seven long-term experimental animals. The reflexive shortening of the animal that had not restored conduction did not sensitize.

\section{DISCUSSION}

Cutting the axon of the $\mathrm{S}$ interneuron, together with other axons in the medial connective nerve, eliminates sensitization of the shortening reflex, as does ablation of an S-cell. Sensitization is restored by regeneration and reconnection of the severed axon with its usual synaptic partner, the axon of S-cell of the adjacent ganglion. This confirms earlier findings that midbody S-cells are essential for sensitization and suggests that the $\mathrm{S}$-cell with its axon is a link in a chain along the animal that mediates sensitization.

The S-cell is but one of many neurons thought to be involved in the leech's whole body shortening (Shaw and Kristan, 1995). Thus, action potentials initiated in the S-cell by an intracellular microelectrode do not by themselves cause this leech to shorten. Moreover, the S-cell normally does not fire during reflexive shortening except when the specimen is sensitized or dishabituated, and killing the S-cell does not interfere with shortening (Sahley et al., 1994), nor does interruption of the S-cell chain (present results). However, S-cells are excited directly by mechanosensory neurons (Gardner-Medwin et al., 1973; Bagnoli et al., 1975), which fire in response to stimuli that produce reflexive shortening. Also, S-cell action potentials produce excitatory synaptic potentials in $\mathrm{L}$ motor neurons (Gardner-Medwin et al., 1973), which are electrically coupled, excite all the longitudinal muscles of their segment and shorten the animal (Stuart, 1970). Because the S-cells themselves are electrically coupled along a rapidly conducting pathway, impulses in the S-cell should contribute to the excitatory drive on the L motor neurons along the length of the animal. It seems, therefore, that S-cells may be made active participants in the shortening circuit by a sensitizing stimulus delivered variously along the length of the animal. Even without considering how the sensitizing signal is conveyed within the nervous system, the mechanisms by which the enhancement occurs are not known. One possibility is that excitatory neurons presynaptic to the S-cell, including the sensory neurons themselves, are more easily activated, or their output is enhanced by the sensitizing stimulus. And the S-cell itself may become more excitable after a sensitizing stimulus.

Although it is evident that the S-cell carries crucial information mediating sensitization, one should consider the possible involvement of additional neurons that may modulate S-cell activity, perhaps indirectly. For example, stimuli that produce sensitization activate cells that release 5-HT, such as the Retzius cells, which influence signaling in mechanosensory neurons (Mar and Drapeau, 1996). Moreover, depletion of 
A

B

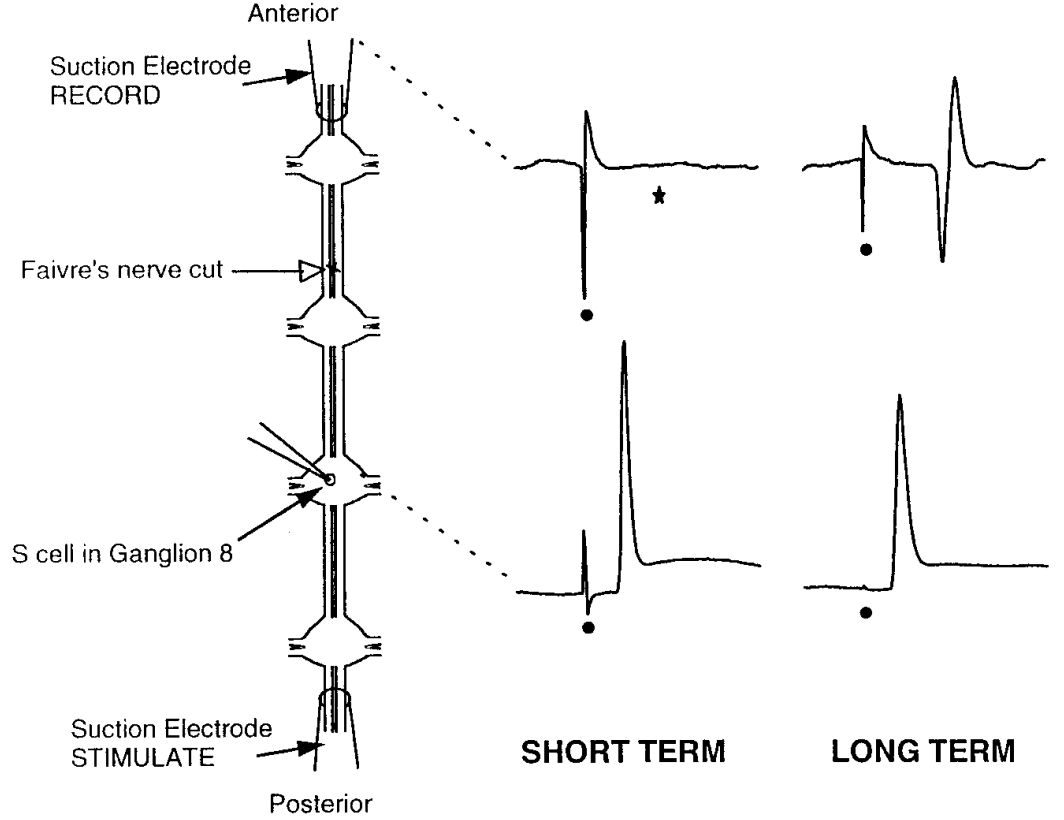

D<smiles>CCCCCCCCCCC</smiles>

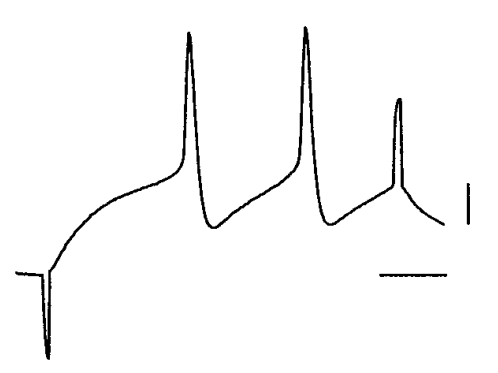

Figure 3. Extracellular stimulation and recording demonstrate disconnection and reconnection of S-cells. $A$, Diagram of preparation for recording, depicting locations of suction electrodes at the ends of the connectives, an intracellular microelectrode in $\mathrm{S}_{8}$, and the lesion site in the medial connective (open arrow) anterior to ganglion 7. B, For short-term specimens, $5 \mathrm{~d}$ after surgery, the impulses elicited in the S-cell by stimulating the connectives extracellularly with the posterior suction electrode did not propagate across the lesion to the anterior suction electrode. Stimulus artifact is marked $(\bullet)$, and the usual location of the propagated extracellular action potential, missing here, is marked $(\star)$. $C$, For long-term specimens, here $78 \mathrm{~d}$, the S-cell impulses propagated across the lesion. In $D$, depolarization of $\mathrm{S}_{8}$ produced a pair of impulses that were also recorded extracellularly. The recording sites on the diagram in $A$ are linked by dashed lines to the corresponding voltage traces in $B-D$. Calibration bars at right for $B$ and $C, 1 \mathrm{mV}$, extracellular trace; $10 \mathrm{mV}$, intracellular trace; and $10 \mathrm{msec}$.

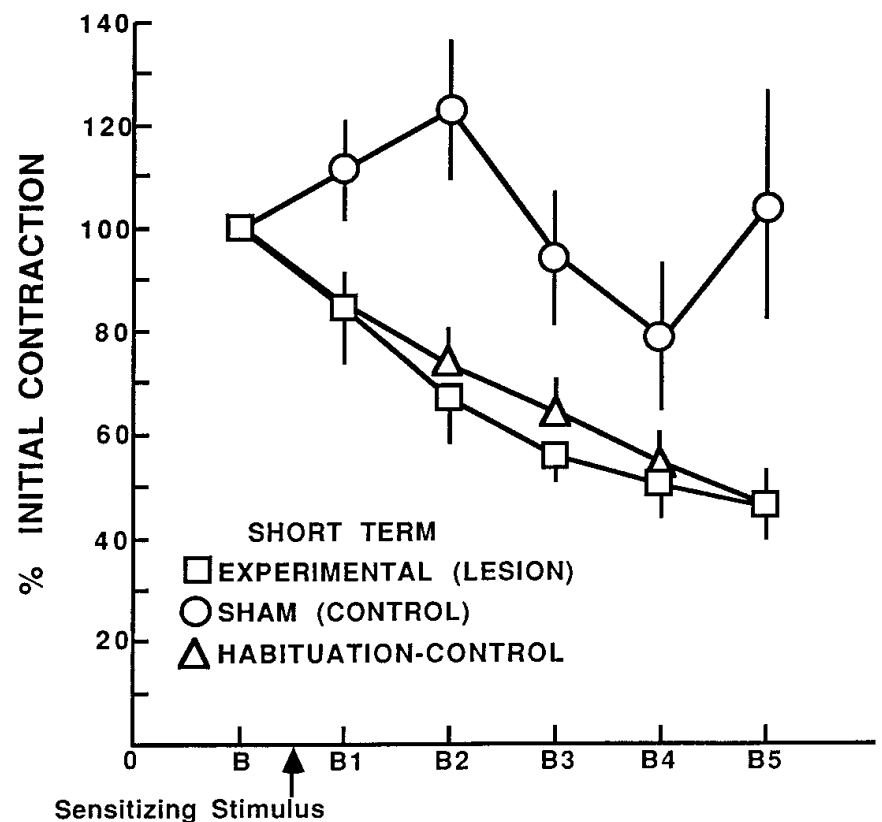

\section{STIMULUS BLOCK \#}

Figure 4. Impairment of sensitization of the shortening reflex by S-cell axon lesions. Shown is the mean percentage of initial contraction for leeches in the experimental (lesion), sham (control), and habituationcontrol groups across habituation training $6-8 \mathrm{~d}$ after cutting the S-cell axon. Leeches in the experimental and control groups experienced a sensitizing stimulus before the onset of repeated presentations of the weak, habituating stimulus, whereas leeches in the habituation-control group did not experience a sensitizing stimulus. Error bars indicate SEM.

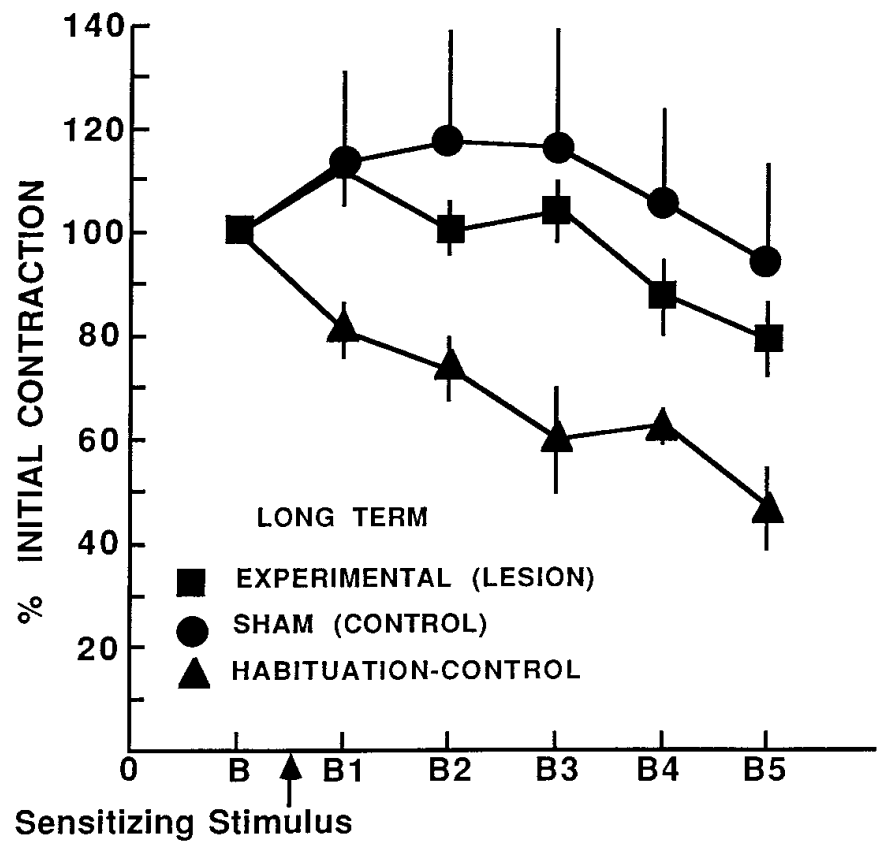

\section{STIMULUS BLOCK \#}

Figure 5. Restoration of behavioral sensitization after regeneration of the S-cell axon. Mean percentage of initial contraction for leeches in experimental (lesion), sham (control) and habituation-control groups across habituation training 3-6 weeks after lesions. The performance of leeches in the experimental group is not different from that in the sham group. They show significant sensitization compared with the habituationcontrol group, which did not experience the sensitizing stimulus. 
5-HT with toxic analogs mimics the effects of S-cell ablation (Ehrlich et al., 1992).

Enhanced firing by the S-cell could have important functional consequences and thus could play an important role in sensitization of the reflex. For example, the increased stimulus-induced activity of the S-cell could selectively augment the release of neuropeptides, as described for other systems (Dutton and Dyball, 1979; Vilim et al., 1996). Consistent with this, the presynaptic terminals of the S-cell within the ganglion contain large dense core vesicles, purported to contain peptide transmitters, in addition to small clear vesicles (Muller and Carbonetto, 1979), and the neuropeptide myomodulin (Cropper et al., 1987) appears by immunocytochemistry to be present in the S-cell (Keating and Sahley, 1996). Thus the postsynaptic action of myomodulin or other peptides might mediate the sensitization-induced increase in behavior. Furthermore, the burst of impulses in the sensitized S-cell might be expected to strengthen its apparent role in the circuit (Lisman, 1997).

That individual, identified neurons can be critical for the generation of reflexive and more complex behaviors in some invertebrates (Jacobs et al., 1986; Muller et al., 1981; Carew and Sahley, 1986; Calabrese and De Schutter, 1992; Hammer, 1993) has been shown previously by cell ablation (Bowling et al., 1978; Selverston and Miller, 1980; Glover and Kramer, 1982), axotomy (Jacobs et al., 1986), and neuronal transplantation (Syed et al., 1992) experiments. Moreover, disrupted behaviors can be restored by regeneration of sensory and motor axons (Dulin et al., 1995; Scott et al., 1995; Steffensen et al., 1995), although recovery of learning has not been examined. Thus, although it is likely that scores or hundreds of neurons may change their activity when behaviors change, a single neuron in one ganglion - the S-cell -is not only required for that plastic behavior but restores that plasticity after axotomy by accurately regenerating synaptic connections.

\section{REFERENCES}

Bagnoli P, Brunelli M, Magni F, Pellegrino M (1975) The neuron of the fast conducting system in Hirudo medicinalis: identification and synaptic connections with primary afferent neurons. Arch Ital Biol 113:21-43.

Boulis NM, Sahley CL (1988) A behavioral analysis of habituation and sensitization of shortening in the semi-intact leech. J Neurosci 8:4621-4627.

Bowling D, Nicholls J, Parnas I (1978) Destruction of a single cell in the central nervous system of the leech as a means of analysing its connexions and functional role. J Physiol (Lond) 282:169-180.

Byrne JH, Crow T (1991) Examples of mechanistic analysis of learning and memory in invertebrates. In: Learning and memory (Kesner R, Martinez J, eds), pp 329-358. New York: Academic.

Calabrese RL, De Schutter E (1992) Motor-pattern-generating networks in invertebrates: modeling our way toward understanding. Trends Neurosci 15:439-445.

Carew TJ, Sahley CL (1986) Learning in invertebrates: from behavior to molecules. Annu Rev Neurosci 9:435-487.

Cropper EC, Tenenbaum R, Kolks MA, Kupfermann I, Weiss KR (1987) Myomodulin: a bioactive neuropeptide present in an identified cholinergic buccal motor neuron of Aplysia. Proc Natl Acad Sci USA 84:5483-5486.

Dulin MF, Steffensen I, Morris CE, Walters ET (1995) Recovery of function, peripheral sensitization and sensory neurone activation by novel pathways following axonal injury in Aplysia californica. J Exp Biol 198:2055-2066.

Dutton A, Dyball RE (1979) Phasic firing enhances vasopressin release from the rat neurohypophysis. J Physiol (Lond) 290:433-440.

Ehrlich JS, Boulis NM, Karrer T, Sahley CL (1992) Differential effects of serotonin depletion on sensitization and dishabituation in the leech, Hirudo medicinalis. J Neurobiol 23:270-279.

Engberg A (1995) Severe traumatic brain injury: epidemiology, external causes, prevention, and rehabilitation of mental and physical sequelae. Copenhagen: Munksgaarde.
Frank E, Jansen JKS, Rinvik E (1975) A multisomatic axon in the central nervous system of the leech. J Comp Neurol 159:1-13.

Freed WJ, de Medinaceli L, Wyatt RJ (1985) Promoting functional plasticity in the damaged nervous system. Science 227:1544-1552.

Gardner-Medwin AR, Jansen JKS, Taxt T (1973) The "giant" axon of the leech. Acta Physiol Scand 87:30A-31A.

Glover JC, Kramer AP (1982) Serotonin analog selectively ablates identified neurons in the leech embryo. Science 216:317-319.

Hammer M (1993) An identified neuron mediates the unconditioned stimulus in associative olfactory learning in honeybees. Nature 366:59-63.

Hawkins RD, Kandel ER, Siegelbaum SA (1993) Learning to modulate transmitter release: themes and variations in synaptic plasticity. Annu Rev Neurosci 16:625-665.

Jacobs GA, Miller JP, Murphey RK (1986) Integrative mechanisms controlling directional sensitivity of an identified sensory interneuron. J Neurosci 6:2298-2311.

Keating HH, Sahley CL (1996) Localization of myomodulin-like immunoreactivity in the leech CNS. J Neurobiol 30:374-384.

Lisman JE (1997) Bursts as a unit of neural information: making unreliable synapses reliable. Trends Neurosci 20:38-43.

Mar A, Drapeau P (1996) Modulation of conduction block in leech mechanosensory neurons. J Neurosci 16:4335-4343.

Mason A, Muller KJ (1996) Accurate synapse regeneration despite ablation of the distal axon segment. Eur J Neurosci 8:11-20.

McClellan AD (1992) Functional regeneration and recovery of locomotor activity in spinally transected lamprey. J Exp Zool 261:274-287.

McGlade-McCulloh E, Muller KJ (1989) Developing axons continue to grow at their tip after synapsing with their appropriate target. Neuron 2:1063-1068.

Muller KJ, Aguayo AJ (1992) Views on regeneration in the nervous system. J Neurobiol 23:467.

Muller KJ, Carbonetto S (1979) The morphological and physiological properties of a regenerating synapse in the C.N.S. of the leech. J Comp Neurol 185:485-516.

Muller KJ, Nicholls JG, Stent GS (1981) Neurobiology of the leech. Cold Spring Harbor, NY: Cold Spring Harbor Laboratory.

Nicholls JG, Baylor DA (1968) Specific modalities and receptive fields of sensory neurons in the CNS of the leech. J Neurophysiol 31:740-756.

Nicholls J, Saunders N (1996) Regeneration of immature mammalian spinal cord after injury. Trends Neurosci 19:229-234.

Sahley CL, Ready DF (1988) Associative learning modifies two behaviors in the leech, Hirudo medicinalis. J Neurosci 8:4612-4620.

Sahley CL, Modney BK, Boulis NM, Muller KJ (1994) The S-cell: an interneuron essential for sensitization and full dishabituation of leech shortening. J Neurosci 14:6715-6721.

Salzman SK, Faden AI (1994) The neurobiology of central nervous system trauma, pp 1-347. New York: Oxford UP.

Scott ML, Li Y, Kirk MD (1995) Functional neural regeneration in the feeding system of Aplysia: behavioral recovery correlated with changes in buccal motor output. J Neurophysiol 73:39-55.

Scott SA, Muller KJ (1980) Synapse regeneration and signals for directed axonal growth in the C.N.S. of the leech. Dev Biol 80:345-363.

Selverston AI, Miller JP (1980) Mechanisms underlying pattern generation in lobster stomatogastric ganglion as determined by selective inactivation of identified neurons. I. Pyloric system. J Neurophysiol 44:1102-1121.

Shaw BK, Kristan Jr WB (1995) The whole-body shortening reflex of the medicinal leech: motor pattern, sensory basis, and interneuronal pathways. J Comp Physiol [A] 177:667-681.

Steffensen I, Dulin MF, Walters ET, Morris CE (1995) Peripheral regeneration and central sprouting of sensory neurone axons in Aplysia californica following nerve injury. J Exp Biol 198:2067-2078.

Stuart AE (1970) Physiological and morphological properties of motoneurones in the central nervous system of the leech. J Physiol (Lond) 209:627-646.

Syed NI, Ridgway RL, Lukowiak K, Bulloch AGM (1992) Transplantation and functional integration of an identified respiratory interneuron in Lymnaea stagnalis. Neuron 8:767-774.

Vilim F, Cropper EC, Price DA, Kupfermann I, Weiss KR (1996) Release of peptide cotransmitters in Aplysia: regulation and functional implications. J Neurosci 16:8105-8114.

Zecevic D, Wu J-Y, Cohen LB, London JA, Höpp H-P, Falk CX (1989) Hundreds of neurons in the Aplysia abdominal ganglion are active during the gill-withdrawal reflex. J Neurosci 9:3681-3689. 